\title{
IMAGE-ACTION Embodiment and Videographic Analysis ${ }^{\dagger}$
}

\author{
Nazario Zambaldi \\ Faculty of Education, Free University of Bozen-Bolzano, 39100 Bolzano, Italy; \\ nazario.zambaldi@education.unibz.it; \\ Tel.: +39-329-676-8999 \\ + Presented at the International and Interdisciplinary Conference IMMAGINI? Image and Imagination \\ between Representation, Communication, Education and Psychology, Brixen, Italy, 27-28 November 2017. \\ Published: 16 November 2017

\begin{abstract}
The following text is part of a doctoral research project entitled "Embodied Education through Art and Theatre. Experimentation of a multimodal interface". Embodied Education includes the contributions of Embodied Cognition, that is, that area of psychological research that represents a "new paradigm" for psychology, shifting from the abstractness of classic cognitive psychology to physicality. "Art" and "Theatre", visual and kinesic channels, are the aspects of physicality that Embodied Cognition addresses, based on the discovery of the so-called MNS, Mirror Neuron System. The case study is aimed at reconsidering methodology and on a theoretical-epistemological rethink regarding images.
\end{abstract}

Keywords: embodied education; videographic analysis; visual thinking; phenomenology

\section{Introduction}

The research hypothesis of this research aims to identify "Embodied Education" [1] (a rare term and one often confused with Embodied Cognition [2,3]) through the didactic experience, in a pedagogical direction [4], that corresponds in particular to the research on Montessori and Embodied Education [5], or even more pertinently on Embodied Education as a convergence between phenomenological pedagogy and Embodiment [6]. This objective-a foundational contribution between Embodied Cognition in psychology and Embodiment in phenomenology (and phenomenological pedagogy) -is pursued also on a philosophical, epistemological, visual and physical level, in the conviction that "Embodiment" and "Embodied Education" imply a mode of thinking as much as a mode of being physical, bodily.

"Abstract" mental thought, which is the form of thought of our logocentric culture [7]-disregarding a visual, corporeal thought -is developed like technology, and at a practical level as an organization of power, as a form of biopolitics [8]. In other words, the separation between the body and mind, between theory and practice, corresponds to a concrete control mechanism, "without body", disembodied. Rudolf Arnheim's "Visual Thinking" intends to go in a different direction from thinking in words [9]. For Arheim, the collaboration between perception and thought, in cognition, would be incomprehensible if such a separation existed. According to Arnheim, even if the Greeks finally divided perception and reasoning, perfecting the techniques of the latter, direct vision remained the first and final source of wisdom: even Aristotle believed "the soul never thinks without an image".

In this framework, emphasizing the "visual" part of the study, we therefore start from the description of the experiment, which uses a mixed learning environment in which the online platform shows the interconnective potential that the iconic, visual, and analog orientation of 
"digital natives" has, as much as it shows the need to embody and create experiences, favoring an ecology of space and mind [10].

Within this mixed methodology, we focus the attention here on the phenomenological videographic analysis, which introduces new theoretical perspectives via observation.

\section{Materials and Methods}

This section discusses "what" and "how" we see, praxis and empirical (experience and experiment): "seeing" here indicates as much the empirical field, as the consciousness that reflexively "sees seeing". In this "mediation", a contextual, empirical mediation through the language between thought and vision, lies the experimental exploration, the "pilot study". This looks as much at the construction of the experiential tools as at testing the empirical tools of observation. Therefore the real experiment, the EMI "interface", is investigated via constructs and models that in phenomenological language are also an "imaginative variation" [11], therefore by phenomenological videographic analysis.

\subsection{Experimental Field}

The research took place in the artistic and human sciences secondary school "Giovanni Pascoli" in Bolzano. The classes involved in the research-2E, 2M, 3D and 3E-were at an intermediary level of study. The teaching language was predominantly Italian.

Regarding the sample (Table 1), participants in the experiment were recruited starting from availability of the Italian and Social sciences teachers. In addition to the teachers involved in the experiment, the pilot phase also involved a psychologist, Rebecca Fill Giordano, an expert in assessing processes of education and learning. There were sixty-two students participating in the experiment in total, the group (GS) that took part in the ECO pilot study in the scholastic year 2014/15, 3D, nineteen, the experimental group (GS) in the effective EMI experimentation in the scholastic year 2015/16, 2M, 20. All the class groups chosen were enrolled in artistic disciplines, 2E, $3 \mathrm{E}, 3 \mathrm{D}$ in pictorial and graphic arts, $2 \mathrm{M}$ in music. 3D and 2M were therefore GS, experimental groups, and the other classes were control groups, GC.

Table 1. Experimental group (GS) and control group (GC) in the two experiment phases.

\begin{tabular}{cccc}
\hline Classes & $\mathbf{N}$ & ECO & EMI \\
\hline $2 \mathrm{E}$ & 11 & GC & GC \\
2M & 20 & GC & GS \\
3D & 19 & GS & GC \\
3E & 12 & GC & GC \\
\hline
\end{tabular}

\subsection{Experimentation}

\subsubsection{ECO}

"The introduction of new digital technologies dethrones language from the role it has played until now as the dominant carrier of the experience of reality, placing a new visuality that is not linguistic but physical at the center of our experience of the world" [12]. The first phase of experimentation, the pilot study, is aimed at syntonizing the learning environment in the visual channel, starting from AR, Augmented Reality. This is assumed to be the cognitive and experiential environment of the current generation of "digital natives" [13], a mixed environment that one can act upon, rather than be subjected to. ECO, Electronic Cooperation Online, is a theatrical artistic project, created and realized by director Pietro Babina. ECO addresses the forms of communication via digital, web, social network, blog, smartphone, tablet, etc. as an augmented reality in which passive participation is transformed into relational, dialogic or narrative competences, with direct involvement through team work, screenplay, staging and video recording. ECO (which also saw the collaboration of Alberto Scocco from the University of Macerata in mapping the organization of the 
work, the construction of the narratives [14], the design, graphics and online hypertext, and the information technology department of the University of Bologna), began as a theatrical experience with professional actors and writers who connected periodically to an online blog (a sort of second life parallel to physical life). They wrote by mixing narrative and daily life, "reality" and fiction, person and character. The "script" that was created in this way was subsequently elaborated (embodied) by the actors with the director in streaming rehearsals, and in multimedia theatrical performances and site-specific installations (with immersive experiences in video scenes shot with $360^{\circ}$ cameras).

The objectives of the educational adaptation (Figure 1) included relational skills, teamwork, reasoning, critiquing, active and creative knowledge of new media, of the language that characterizes it and of augmented reality (AR), that is, the mixed environment that characterizes contemporary "experience".

The phases of the seminar activity were concentrated in around twenty class hours, after a methodological and theoretical introduction. They can be summarized as:

- using mapping, the students write their names individually on paper and then on the board, visualizing the variable relationships in the group

- two groups are organized as collective identities

- a blog is opened as a shared platform

- the two groups work on computers in separate rooms

- the conductor posts an image on the blog, beginning an online dialogue

- each group has a turn with a fixed time limit to respond to the message sent by the other group (in addition to words, they may use images, sounds, video and whatever else is available on the platform)

- when the conductor or the participants feel they have a meaningful dialogue, they move to the second phase, reuniting the groups.

- in this transcoding phase, they re-read the text and adapt it as a screenplay that can be video recorded

Let us linger on this moment, which is the phase of embodiment of the text, that is, where the incompleteness of the online communication emerges, insofar as it is disembodied. The online dialogue shows an absence of context, setting, physical characteristics, psychology. To construct a setting, characters, situations, and psychology, we use mapping, which becomes a visual tool of that connective intelligence that is used not just online but also in the physical environment [15].

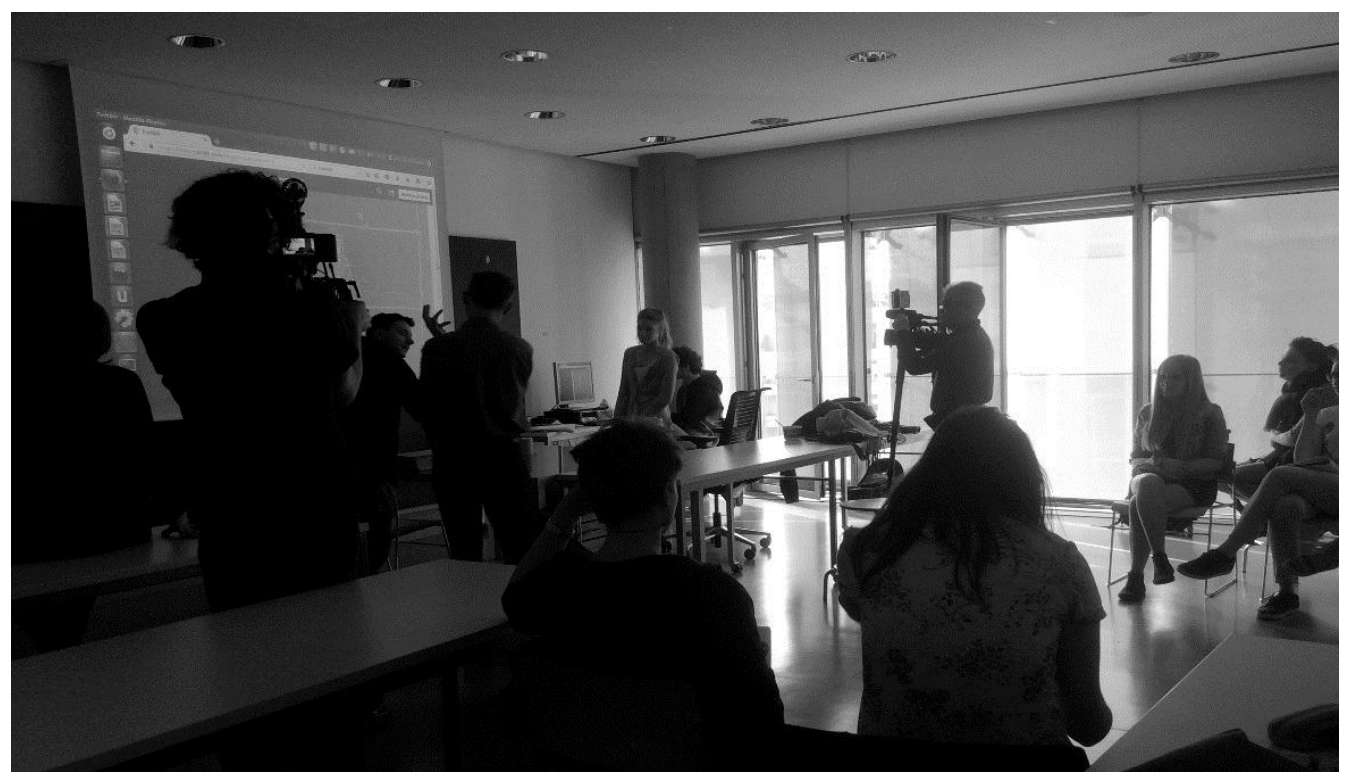

Figure 1. ECO, rehearsal of the interpretation of the dialogue and group proof of its efficacy. 


\subsubsection{EMI}

The actual experiment - for a total of around twenty hours distributed as weekly activities over a trimester-integrated both the ECO activity and the tools that the observations of the pilot study were based on. In particular the EMI, Experiential Multimodal Interface, construct inherited elements from ECO, such as the initial setting, the mapping to represent thoughts, images and actions, and the dialogue realized online, as the basis for a narrative embodiment, integrating it with theatrical training as a "work on the self" [16]. Here we revisit the aspects that integrated the EMI with a "meet and greet" (Figure 2), a simple introductory exercise from theatrical training that translates the extended mind into physical space [17], intersubjective (and intrasubjective), the mental extension of the web:

- conscious breathing in a circle, with eyes closed, similar to several experiential environments-mindfulness, yoga, relaxation-visualizing the parts of the body

- free exploration of the classroom space, the students are prompted with the mental image of the classroom space as the board where their names were written and as white paper, with eyes open, moving in the space in a relaxed manner

- visual contact and offering of hands in greeting, when the students meet, they stop in front of each other and offer their hand, looking in each other's eyes

This-literal-contact with oneself, others and the space, opens visual channels beyond mental images, or the representation in the framework of the computer or other supports, to perception, bodily representation and visual-spatial coordination. Without going into more detail here on aspects that are addressed in depth in the thesis, multiple studies have indicated a certain continuity between graphical interfaces and natural visual communication. Graphical interfaces represent a return to a form of visual alphabetization prevalent in the ancient pictorial alphabets, favoring the development of good visual memory and intuitive-associative thought [18], which helps to decode visual messages. Visual contact makes this orientation of "digital natives" relational and embodied, creating a temporal space, a present experience.

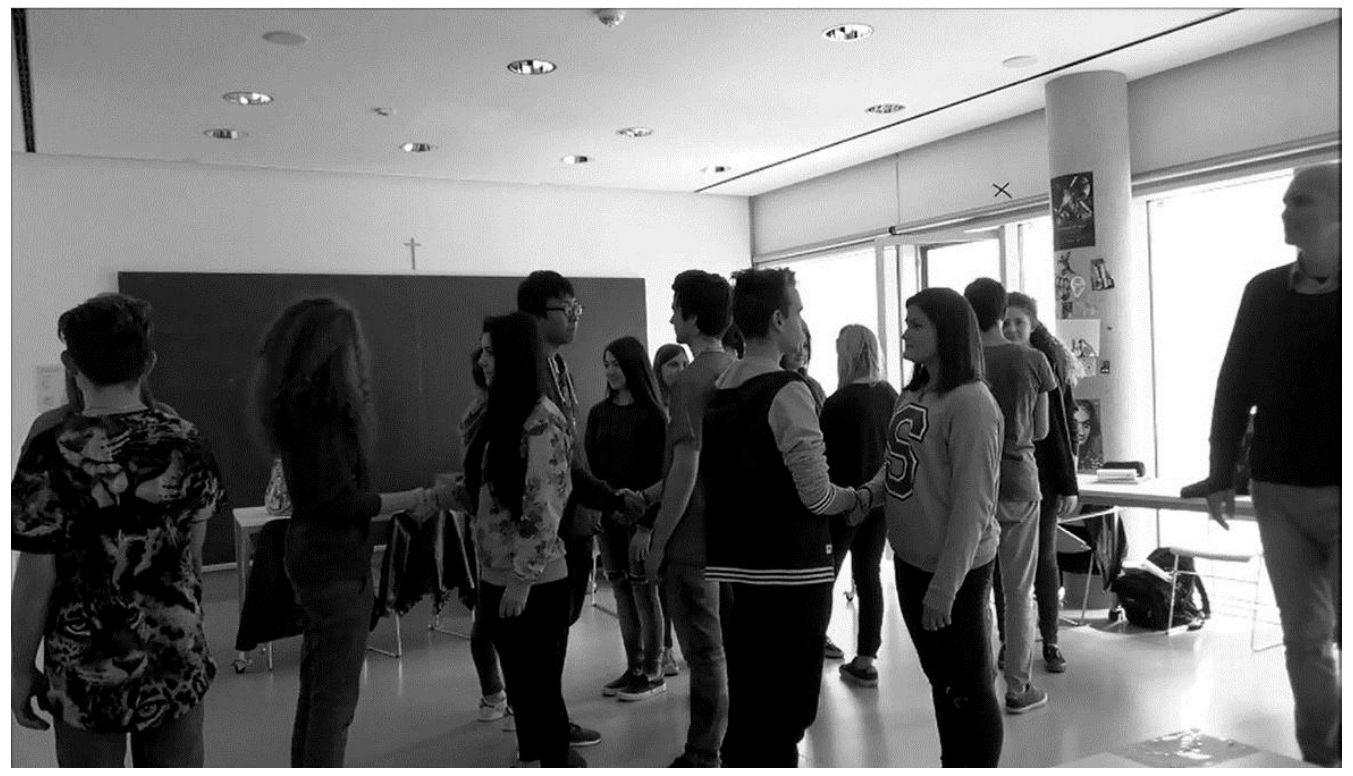

Figure 2. EMI, movement in the classroom and meet and greet: visual contact.

\subsubsection{Mixed Method as "Imaginative Variation"}

I would like to mention the mixed approach here, although within the limits of this presentation which aims to be an initial introduction to the phenomenological videographic method. I will describe the experiential setting based on a multimodal approach, that is, organized as visual and 
kinesic channels, rather than just abstract, amodal transmission, which still frames the contexts of learning at school according to traditional cognitivist training.

Beyond the minimum horizon of a case study that measures effectiveness in experimentation by measuring pre- and post-test variations in those constructs that demonstrate an Embodied Education, or rather an Embodiment, such as agency, self-efficacy, self-awareness, self-consciousness, we also wish to frame this mixed methodology in a phenomenological perspective. Husserl defined this as an imaginative variation [11], a descriptive approach in which the things are not understood in their entirety, but rather through prospecting, exploring around them. At this level of quasi-experimental research or case study, we conducted pre- and post-test questionnaires (in stages $\mathrm{t} 1$ and $\mathrm{t} 2$, for the ECO pilot study and in stages $\mathrm{t} 3$ and $t 4$, for the EMI effective experimentation) on agency [19], self-efficacy [20-22], self-consciousness [23], self-awareness [24], empathy and other specifics on body and space (virtual or AR Augmented Reality and material or MR Material Reality). There was also an analysis of variance (ANOVA), and qualitative questionnaires were also administered, in a retrospective interview in the experimental group [25]. Pre- and post-test questionnaires were also administered in order to conduct a sociometric analysis $[26,27]$.

\subsubsection{Phenomenological Videographic Analysis}

An image is in itself a structure that recalls the main source of every form of knowledge that is perception. Therefore images are essential from the phenomenological point of view, because they refer back to the fundamental element of consciousness that is perception. The phenomenological videographic analysis introduced here starts by distancing itself from the forms of critical-reconstructive interpretation of experience.

In this approach, we find "eine phänomenologische Kritik der hermeneutischen und rekonstruktiven Verfahren" [28], a phenomenological critique using a hermeneutic and reconstructive process. In particular recalling Heidegger: „Faktisch ist es [...] so, dass unsere schlichtesten Wahrnehmungen und Verfassungen schon ausgedrükte, mehr noch, in bestimmter Weise interpretierte sind. Wir sehen nicht so sehr primär und ursprünglich die Gegenstände und Dinge, sondern zunächst sprechen wir daruber, genauer sprechen wir nicht das aus, was wir sehen, sondern umgekehrt, wir sehen, was man uiber die Sache spricht", "and so it is a fact (...), that our simplest perceptions and appearances are already expressed, and moreover, are in some way (already) interpreted. We do not see objects and things in a primary and original way, but rather we speak of them only later, more precisely we do not express in words, what we see, but on the contrary, we see what is spoken of through language" [29].

We find ourselves finally in a dimension of real phenomenological analysis of the video images, analysis of appearances, the reductive dimension of the epochè, suspension of judgement in which the imaginative variations operate. This methodology was created and is practiced at Berlin's Humboldt University in the group directed by Malte Brinkmann. It deals with a "Theorie der pädagogischen Erfahrung", theory of pedagogical experience in which the experience as a pedagogical experience is determined as much by the subjective praxis as by the social element of learning and education. This determination of the experience of learning is demonstrated (gezeichnet) via intentionality (Intentionalitat). Merleau-Ponty's role would be to reconnect phenomenological theory of the experience into a corporeal phenomenological perspective (in leibphänomenologischer Perspektive weiter ausgearbeitet), that is, in the non and pre-verbal, pre-reflective, carrying back the transcendental subject of Husserl to a bodily, real subject [30].

Beyond the theoretical aspects, we describe here this Pälagogische Empirie, empirical pedagogy, of the pedagogical experience, in the field of the body and power at the meeting point between subjective and social sense, which is operationalized through the following pedagogic dimensions which structure the brief discussion:

- Verköperung, embodiment or incarnation

- kommunikative Relationierung im Antwortgeschehen, relational communication in the response, "responsivity" [31] 
- die Praxis und die Form des auf Aufmerksamkeit zielendes Zeigens, the praxis and the form of showing (Zeigen) the paying of attention (Aufmerksamkeit)

These three operationalizations are intended to be descriptive categories in a phenomenological methodology. This movement between theory, the empirical and praxis, via reduction and phenomenological variation identifies three moments in the videographic analysis as descriptive categories:-Verkörperung (Embodiment)-Antwortgeschehen (Responsivity)-Zeigen (Aufmerksamkeit), show (attention) - which guide the protocol of the videographic analysis.

\section{Results and Discussion}

Speaking of results makes sense for the part which we have nodded to here in a phenomenological perspective as imaginative variation, descriptive. In particular, the statistical analysis has furnished several significant data $(p<0.05)$, in the scale that measured aspects linked to bodily awareness (with questions such as "The quality of breathing influences my attention" or "I am comfortable if looking (or looked at) in the eyes"), and in the scale relative to private and public "situational" self-awareness (with items such as "In this moment, I am aware of my internal emotions" or "In this moment, I am reflecting on my life"). Several considerations in the scale related to self-consciousness were also significant (with reflections like "I am easily embarrassed", "I am aware of my appearance", "It's easy for me to talk with strangers", "In general I listen to my internal emotions"), and the perceived agency in managing positive and negative emotions. In fact, the values measured after the experimentation were actually lower. The hypothesis is that these contradictory results indicate an increase in awareness of these aspects.

This significance was then validated in the Qualitative Analysis of Contents of the texts of the interviews during activities, according to Mayring's content analysis method, in which the textual materials-derived from the questionnaire responses to open questions by the participants in the study-were regrouped according to inductive categories, or through a generalization of the content [25].

The sociographic analysis related to emotional-relational and organizational pre- and post-test levels [26,27], which represents the variations on the basis of the involvement in the EMI, even showed interesting modifications in the experimental group, which went in the direction of a true breakdown of personal patterns as well as real social stereotypes. In these, the most obvious were the ones related to genre. The spontaneous groups, which are more habitual and fixed associations rather than interpersonal growth, even solely based on an introduction to a limited experiential pathway such as the one studied, were opened by introducing dynamic elements.

The value of the investigation, which focused on the correlation between an activity oriented on embodiment and the adopted constructs, was in any case descriptive, given the small sample and the almost-experimental characteristics of the research. The context nonetheless leaves space for a typically descriptive perspective of the phenomenological imaginative approach. As mentioned, we will look at a few examples, here briefly discussing some video observations.

Verkörperung, Embodiment: according to Merleau-Ponty [30], in the habitual bodily patterns the self should emerge, the awareness more of a possibility ("I can") than of a thought ("I think"). In this physicality and lived experience, Leib, Erlebnis, the false dualism between body and spirit is overcome, with naturalism on one side and rationalism (cognitivism) on the other. The phenomenological videographic description of the physicality, Leiblichkeit, also suspends the dualism between interior sense and external behavior. Therefore we draw attention through images to these emergences, appearances, in the non-verbal language of gestures, in mimicry, attitudes. In this eccentric space of identity and presence we find an educational embodiment, the roll-call (Figure 3), from the recording of the Italian lessons in the school and classes which hosted the experiment. What we can see is the scholastic setting, habitual, in which at school "one cannot change place". Objects are central in this emergent presence, the arrangement of desks, the projection screen pulled down in front of the blackboard. The teacher in the central position, the first row of students closest to the teacher, with their backs to the others. We can assist in a first version of what Brinkmann described as a pedagogical staging of the construction and maintenance of order in 
the horizon of repetition and power ("pädagogische, ordnungsbildende und ordnungserhaltende Inszenierung im Horizont von Wiederholung und Macht beschreibbar") [28].

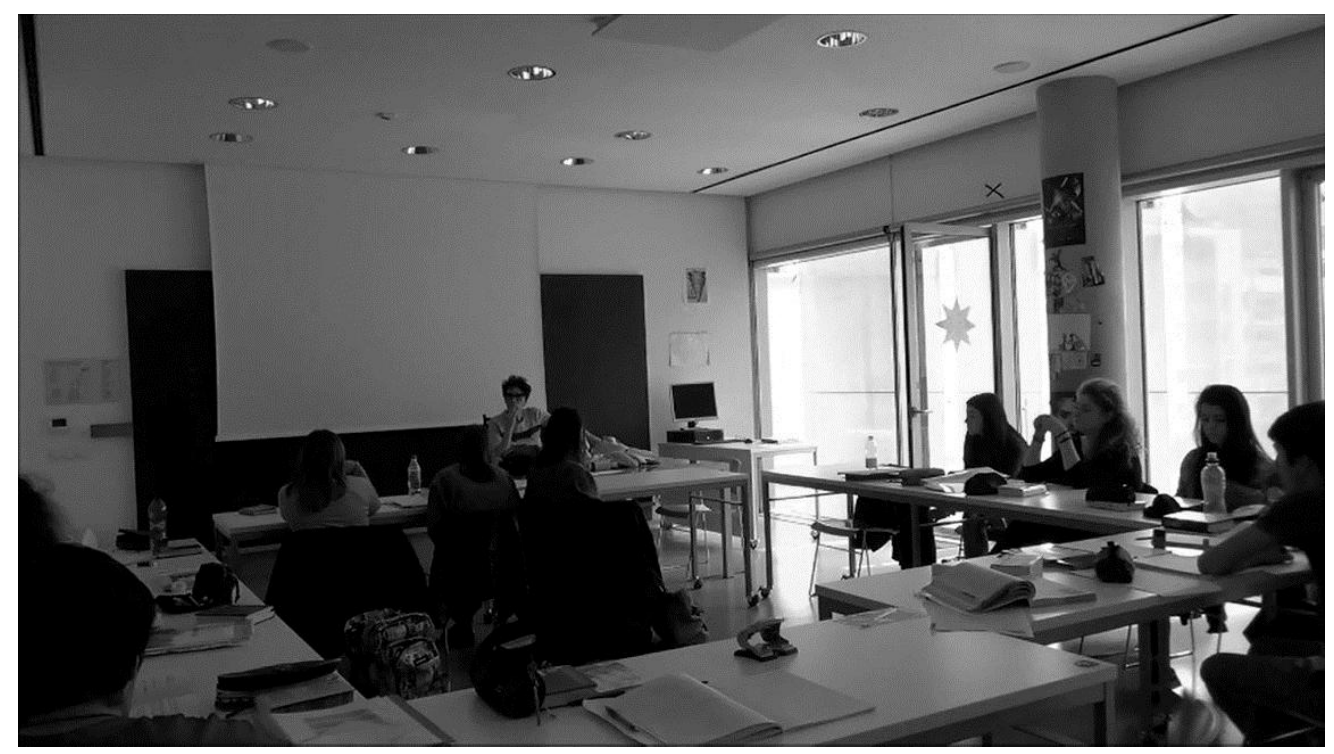

Figure 3. Verkörperung (Embodiment): roll-call in the Italian lesson.

Zeigen, attention: Heidegger, in the preface to Richardson's work on phenomenological thinking, notes "through the immediate experience of the phenomenological method, speaking with Husserl, the concept of phenomenology was elaborated, as it is explained in the introduction of Being and Time. In it, "retrorelation" (Ruckbeziehung) plays a fundamental role, with the corresponding fundamental words (Grundworte) of Greek thought: logos (make manifest) and phainesthai (show)" [32]. In presenting more than representing the images, the "show" and "show oneself", Zeigen sich-Zeigen, is directly connected with learning and education [28]. Also in Italian show and demonstrate are part of the tradition oriented toward vision and evidence of scholastic explaining. The verb zeigen can be translated with indicate, in the sense of mark, therefore to teach. In the image relative to the EMI experience (Figure 4) in the dialogue even more than the words, the looks, the expressions of faces, demonstrate listening, attention, which seems to be reflected in the behavior of those present.

In the proposal that follows, as indicated in the title, we find, in addition to the two presented above, the third moment of the videographic analysis: Antwortgeschehen (responsivity). In the work of the phenomenological videographic analysis, in the Forschungkolloquium at the Humboldt University directed by Malte Binkmann, with whom I participated together with lecturers, researchers and doctoral students, the analysis was directed at frames, images extracted from videos of lessons and educational situations. The observation and analysis is proposed here as a variation, because the analysis passes from individual significant images - "still" - to "moving" images, and so we will refer to the concept introduced in the text dedicated to the cinema of philosopher Gilles Deleuze [33]. In the "images-action" (Figure 5), thanks to the sequence "we see what we see" (we imagine it). Students meet for the "greeting". 


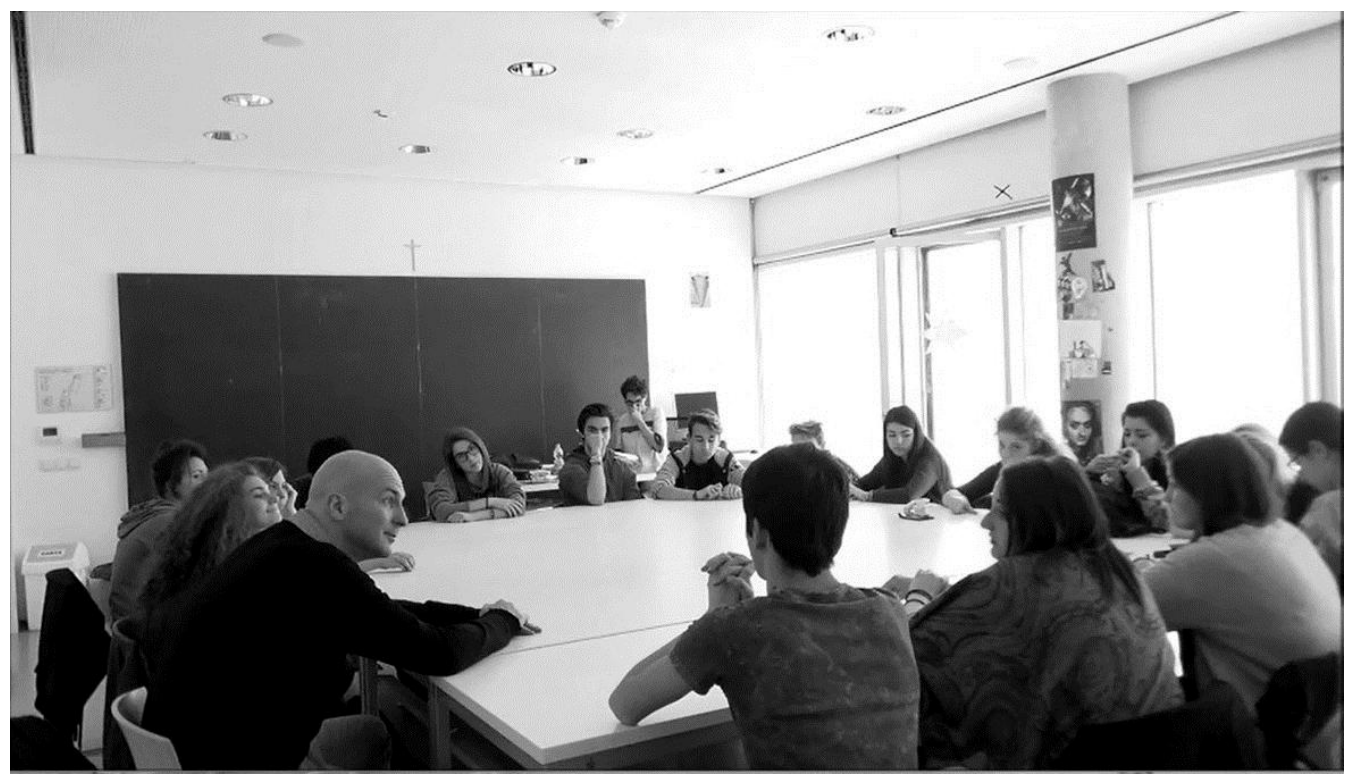

Figure 4. Zeigen (showing): discussion during EMI.

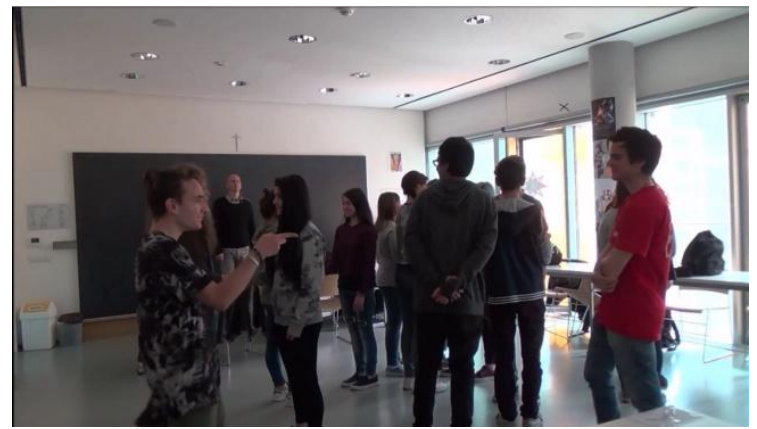

(a)

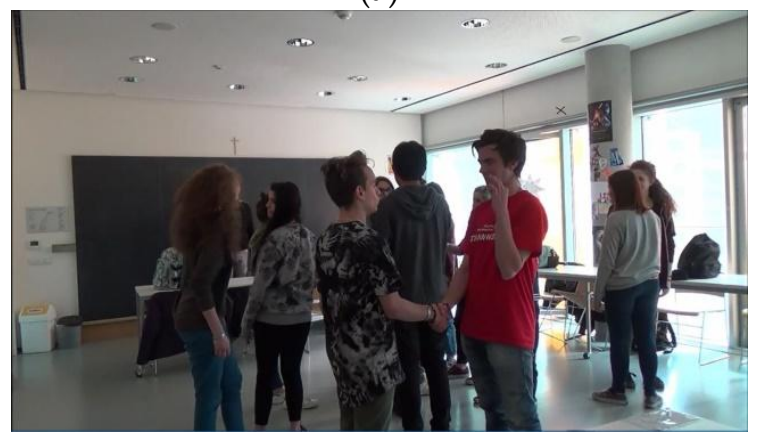

(c)

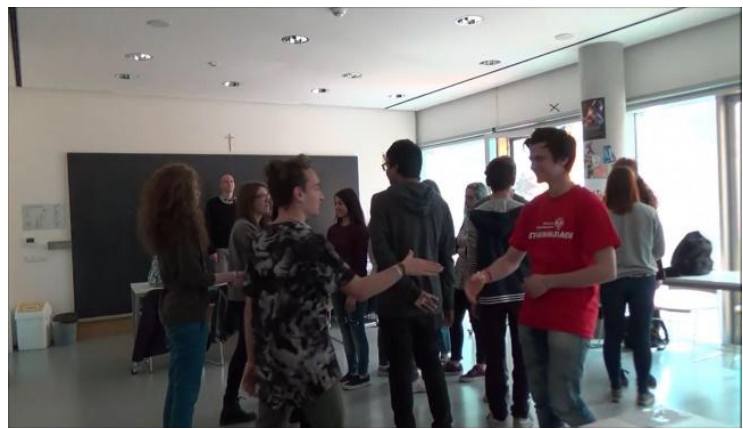

(b)

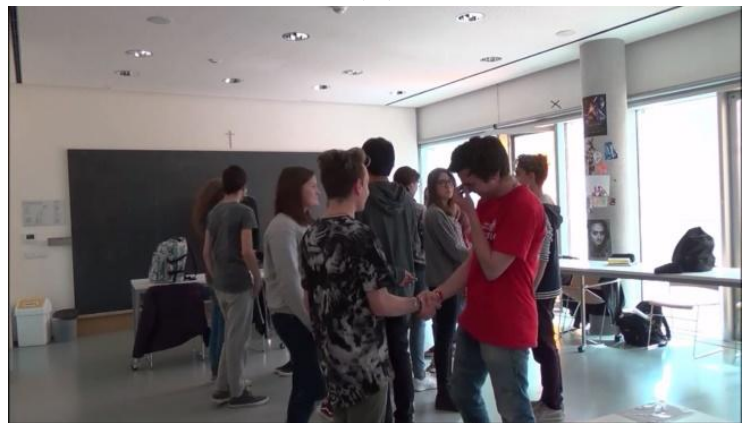

(d)

Figure 5. Images-action: (a) visual contact from a distance; (b) coming closer; (c) physical contact; (d) laughter as an event that breaks the structure of the exercise.

It deals with the exercise of theatrical training which opens the activity and which can be protracted at length, until the acquisition of a consciousness and awareness extended to the entire scene, the work environment. But what is interesting for the aims of the videographic analysis is an event [34], which is differentiated from the phenomenon because it breaks the contextual framework, that is, the proposed exercise. In Verkörperung in a close up, one student embodies, indicating, calling the other, who responds with responsivity-Antwortgeschehen-made of gestures. The one on the right responds to the extended hand (Responsivität). Therefore in the resting position, it falls to the person on the right to show-zeigen-always coming out and anticipating the event of laughing which breaks the pattern, phenomenal, physical, therefore ecological, environmental, so that the laughter communicates to the others. Bergson, whose study on duration inspired Deleuze in the cited text [33], dedicates an essay to laugher as "breaking the pattern" [35]. The paradox of seeing 
movement in still images next to each other, that is the cinema, or video, reveals a perceptual mechanism and together the spatial-temporal geometricization of the representation of reality. The image-action is therefore evidence of a paradox that dates back to Zenone, and at the same time in Merleau-Ponty's intentional arc [36], sense of the present as movement, revealing that dynamic synthesis that is subjective perception. Image-action: imagination.

\section{Conclusions}

The intention of this piece is to present-demonstrate-an experiment that started from the imaginative dimension of embodiment. Highlighting how this involves the integration of conceptual thinking with thinking through images. Therefore introduce what from the start of this study is being developed as an exercise on images (and imagination), videographic analysis.

Starting therefore from the research, which took its shape from the phenomenological distinction between Leib and Körper [37], lived body and physical body, seeking lived experience Erlebnis in the embodied education, which cognitive neuroscience re-evaluates as the basis of comprehension and therefore of learning, here at various levels we reclaim the visual orientation of the research: the image guides both the theoretical level-a thought of the vision-and the experiment, the methodological approach and the experiential setting. This visual, analogical, and abductive thought [38], the so-called thought of discovery, is particularly coherent with the exploratory dimension of human sciences.

The imaginative variations that are the foundation of the adoption of the various models and constructs on a psychological-and psychopedagogical-plane, showcase the preliminary and recursive constructive play between subjectivity and inter-subjectivity. The adoption in the experiential didactic practice of a thinking that interconnects, starting from the web, the mapping as a structuring of this prevalently visual dimension, between virtual and material reality, the video recording as a synthesis, various repetitions, offer effective tools in the social and relational contexts that are fundamental bases of education at school.

The phenomenological videographic analysis can represent here the possibility to collect, in addition to other documenting aspects, significant events, to the extent that they reveal transformative potential, or rather going beyond observation of phenomena, to the identification of pedagogical events. To do this as proposed here it is necessary to move on from frames as still images, which on another plane is reality in its mathematical reduction. In education the learner is still and silent, isolated, present insofar as they are absent, in the image action, which underlies a consciousness in action, intentional, present in movement, imagination.

The transmission of knowledge is made effective by the images that make the context significant, showing intentions and scopes as asserted by Gallese [39], or also as demonstrated in Lakoff's studies [40] of a metaphorical communication that is speaking via images: "if I imagine, I understand" [41].

The interface or "educational mediator" [42], EMI, visual and physical, aimed at achieving Embodied Education in the experiment, identified Embodiment in the phenomenological videographic analysis as the very substance of learning, or of the pedagogical or didactic experience. This brings us back to the practical plane, as well as the theoretical one of visual thought, to the origin of our culture, the Greek Paideia. In this sense, the videographic analysis is a tool to show Embodiment as the realization of learning.

Through an image that seems evocative we can concur with Gallese, who in "The Empathic Screen. Cinema and mirror neurons" [43] underlines how the tracking shot is more effective for identification compared to the fixed camera. Gallese and Guerra use a brief clip from the film Notorious by Alfred Hitchcock. In one scene it uses a "first-person perspective", a technique much used in the forties and fifties, in which the spectator identifies with Ingrid Bergman. We seem to be going to fetch a bunch of keys. In reality she is standing still in one part of the room: it is only the camera that moves. 
Conflicts of Interest: The author declares no conflict of interest.

\section{References}

1. Zambaldi, N. Embodied Education al centro di un nuovo paradigma: Un contributo da arte e teatro per un interfaccia multimodale. Form. Insegn. 2016, 14, 333-339.

2. Rizzolatti, G.; Fadiga, L.; Fogassi, L.; Gallese, V. Premotor cortex and the recognition of motor actions. Cognit. Brain 1996, 3, 131-41.

3. Fadiga, L.; Craighero, L. New insight on sensorimotor integration: From hand action to speech perception. Brain Cognit. 2003, 53, 514-524.

4. Rizzolatti, G.; Sinigaglia, C. So Quel Che Fai, Il Cervello Che Agisce e i Neuroni Specchio; Raffaello Cortina: Milano, Italy, 2006.

5. Rathunde, K. Montessori and embodied education. In Alternative Education in the 21st Century: Philosophies, Approaches, Visions; Woods, P., Woods, G., Eds.; Palgrave Macmillan: New York, NY, USA, 2009; pp. 189-208.

6. Tarozzi, M.; Francesconi, D. Embodied Education. A Convergence of Phenomenological Pedagogy and Embodiment. Stud. Phaenomenol. 2012, 12, 263-288.

7. Derrida, J. Della Grammatologia; Jaca Book: Milano, Italy, 1969.

8. Foucault, M. La Volontà di Sapere; Feltrinelli: Milano, Italy, 1978.

9. Arnheim, R. Il Pensiero Visivo; Einaudi: Torino, Italy, 1974.

10. Bateson, G. Verso Un'Ecologia della Mente; Adelphi: Milano, Italy, 1977.

11. Husserl, E. Meditazioni Cartesiane; Bompiani: Milano, Italy, 1960.

12. Gallese, V. Arte, Corpo, Cervello. Per un'Estetica Sperimentale. Micromega 2014, 2, 49-67.

13. Prensky, M. Digital Natives, Digital Immigrants Part 1. Horizon 2001, 9, 1-6.

14. Scocco, A. Costruire Mappe Per Rappresentate e Organizzare Il Proprio Pensiero; Franco Angeli: Milano, Italy, 2008.

15. De Kerckhove, D. Connected Intelligence. The Arrival of the Web Society; Somerville House Books: Toronto, ON, Canada, 1997.

16. Alschitz, J. La Grammatica Dell'Attore. Il Training; Ubulibri: Milano, Italy, 1998.

17. Clark, A.; Chalmers, D. The extended mind. Analysis 1998, 58, 7-19.

18. Snyder, I. Renegotiating the visual and the verbal communication. Prospect 1999, 1, 13-23.

19. Bandura, A. Autoefficacia: Teoria e Applicazioni; Erickson: Trento, Italy, 2000.

20. Caprara, G.V. La Valutazione Dell'auto-Efficacia. Costrutti e Strumenti; Erickson: Trento, Italy, 2001.

21. Chen, G.; Gully, S.M.; Eden, D. Validation of a New General Self- Efficacy Scale. Organ. Res. Methods 2001, $4,62-83$.

22. Sibilia, L.; Schwarzer, R.; Jerusalem, M. Italian Adaptation of the General Self-Efficacy Scale: Self-Efficacy Generalizzata, 1995. Available online: http://userpage.fuberlin.de/ health/italian.htm (accessed on 10 November 2017).

23. Scheier, M.F.; Carver, C.S. The Self-Consciousness Scale: A revised version for use with general populations. J. Appl. Soc. Psychol. 1985, 15, 687-699.

24. Govern, J.M.; Marsch, L.A. Development and validation of situational self-awareness scale. Conscious. Cognit. 2001, 10, 366-378.

25. Mayring, P. Qualitative Inhaltsanalyse. Grundlagen und Techniken; Deutscher Studien Verlag: Weinheim, 1983.

26. Moreno, J.L. Sociometry in the classroom. Sociometry 1943, 6, 425-428.

27. Bastin, G. Le Tecniche Sociometriche; Società editrice internazionale: Torino, Italy, 1963.

28. Brinkmann, M. Pädagogische Erfahrung: Theoretische und Empirische Perspektiven; Springer: Berlino, Germany, 2015.

29. Heidegger, M. Sein und Zeit, 18th ed.; Niemeyer: Tübingen, Germany, 2001.

30. Merleau-Ponty, M. Phänomenologie der Wahrnehmung, 6th ed.; Walter de Gruyter Verlag: Berlin, Germany, 2011.

31. Waldenfels, B. The Question of the Other; Chinese University Press: Hong Kong, China, 2007.

32. Richardson, W.J. Heidegger: Through Phenomenology to Thought, 4th ed.; Fordham University Press: New York, NY, USA, 2003.

33. Deleuze, G. L'Immagine-Movimento. Cinema 1; Ubulibri: Milano, Italy, 1984. 
34. Deleuze, G. Logica del Senso; Feltrinelli: Milano, Italy, 1975.

35. Bergson, H. Il Riso. Saggio sul Significato del Comico; Rizzoli: Milano, Italy, 1961.

36. Merleau-Ponty, M. Fenomenologia della Percezione; Bompiani: Milano, Italy, 1965.

37. Husserl, E. La Crisi delle Scienze Europee e la Fenomenologia Trascendentale; Il Saggiatore: Milano, Italy, 1987.

38. Peirce, C.S. Opere; Bompiani: Milano, Italy, 2003.

39. Gallese, V.; Goldman, A. Mirror neurons and the simulation theory of mind-reading. Trends Cognit. Sci. 1998, 12, 493-501.

40. Lakoff, G.; Mark J. Metaphors We Live by; University of Chicago: Chicago, IL, USA, 1980.

41. Mario, D. Se Immagino Capisco. Il ruolo dei Processi Simulativi e Metaforici Nella Comprensione del Testo. Ph.D. Thesis, Università Ca' Foscari, Venezia, Italy, 2011.

42. Damiano, E. I Mediatori Didattici. Un Sistema D'analisi Dell'insegnamento; IRRSAE: Milano, Italy, 1989.

43. Gallese, V.; Guerra, M. Lo Schermo Empatico. Cinema e Neuroscienze; Raffaello Cortina: Milano, Italy, 2015.

(C) 2017 by the authors. Licensee MDPI, Basel, Switzerland. This article is an open access article distributed under the terms and conditions of the Creative Commons Attribution (CC BY) license (http://creativecommons.org/licenses/by/4.0/). 